\title{
Sensory Relevance of Strecker Aldehydes in Wines. Preliminary Studies of Its Removal with Different Type of Resins
}

\author{
Almudena Marrufo-Curtido ${ }^{1}$, Arancha de-la-Fuente-Blanco ${ }^{1}{ }^{\circledR}$, María-Pilar Sáenz-Navajas $\left.{ }^{2}{ }^{(}\right)$, Vicente Ferreira ${ }^{1}{ }^{(0)}$, \\ Mónica Bueno ${ }^{1}$ (D) and Ana Escudero ${ }^{1, *(D)}$ \\ 1 Laboratorio de Análisis del Aroma y Enología (LAAE), Department of Analytical Chemistry, \\ Universidad de Zaragoza, Instituto Agroalimentario de Aragón (IA2) (UNIZAR-CITA), Associate Unit to \\ Instituto de las Ciencias de la Vid y del Vino (ICVV) (UR-CSIC-GR), c/Pedro Cerbuna 12, 50009 Zaragoza, \\ Spain; amarrufo@unizar.es (A.M.-C.); arandlfb@unizar.es (A.d.-l.-F.-B.); vferre@unizar.es (V.F.); \\ mobueno@unizar.es (M.B.) \\ 2 Department of Enology, Instituto de Ciencias de la Vid y del Vino (CSIC-GR-UR), Finca La Grajera, \\ Ctra. de Burgos Km. 6 (LO-20—Salida 13), 26007 Logroño, La Rioja, Spain; mpsaenz@icvv.es \\ * Correspondence: escudero@unizar.es
}

check for updates

Citation: Marrufo-Curtido, A.; de-la-Fuente-Blanco, A.; Sáenz-

Navajas, M.-P.; Ferreira, V.; Bueno, M.;

Escudero, A. Sensory Relevance of Strecker Aldehydes in Wines. Preliminary Studies of Its Removal with Different Type of Resins. Foods 2021, 10, 1711. https://doi.org/ $10.3390 /$ foods 10081711

Academic Editor: Onofrio Corona

Received: 30 June 2021

Accepted: 22 July 2021

Published: 23 July 2021

Publisher's Note: MDPI stays neutral with regard to jurisdictional claims in published maps and institutional affiliations.

Copyright: (c) 2021 by the authors. Licensee MDPI, Basel, Switzerland. This article is an open access article distributed under the terms and conditions of the Creative Commons Attribution (CC BY) license (https:/ / creativecommons.org/licenses/by/ $4.0 /)$

\begin{abstract}
The orthonasal quality of two synthetic contexts of wine (young wine and oaked wine) spiked with six different levels of the Strecker aldehydes (isobutyraldehyde, 2-methylbutanal, 3-methylbutanal, methional and phenylacetaldehyde) was evaluated by a panel of wine experts. The aldehyde levels simulated the concentrations present in wines protected from oxidation during production and storage and after severe oxidation. Significant quality detriments were observed at concentrations of $13 \mu \mathrm{g} / \mathrm{L}$ of methional, $49 \mu \mathrm{g} / \mathrm{L}$ of phenylacetaldehyde, $17 \mu \mathrm{g} / \mathrm{L}$ of isobutyraldehyde, $12 \mu \mathrm{g} / \mathrm{L}$ of 2-methylbutanal and $24 \mu \mathrm{g} / \mathrm{L}$ of 3-methylbutanal. The presence of these levels of aldehyde concentrations induced the reduction of fruitiness in young wines and of woody notes in oaked wines as well as the appearance of the typical attributes that define wine oxidation. More than $75 \%$ of recently opened commercial wines contain total levels of Strecker aldehydes higher than those, however their effect is not always noticeable as they are forming inodorous adducts with $\mathrm{SO}_{2}$. Nevertheless, this content is a potential risk for the shelf life of the wine, as once $\mathrm{SO}_{2}$ is depleted, these aldehydes could release back into their odour-active forms. Thus, in order to reduce the presence of Strecker aldehydes, eight different resins were studied (two scavengers, four mixed-mode anion exchange and two pure anion exchange) in white wine at two levels of $\mathrm{SO}_{2}$. After 24-h contact, the mixed mode Strata X-A resin was able to significantly reduce aldehydes' percentages: between $11 \%$ for isobutyraldehyde and $86 \%$ for phenylacetaldehyde. On the other hand, wine colour was affected and therefore the applicability of the treatment should be further studied. However, this work can be considered a starting point to solve the technological challenge involved in the elimination of aldehydes from wine.
\end{abstract}

Keywords: strecker aldehydes; oxidation; acetaldehyde; resins; orthonasal quality; aldehyde removal

\section{Introduction}

During bottle ageing, wines are in contact with oxygen to a greater or lesser extent. However, not all wines endure this ageing and oxidise. The clearest symptoms of oxidation are the evolution of wine colour towards yellow and brown hues [1] and the appearance of the oxidised aroma [2]. Usually, the latter happens before wine browning becomes obvious [3,4], even leading to wine spoilage. In fact, $48 \%$ of wines identified as faulty in several oenological contexts have defects related to inadequate ageing, in particular with aroma-related oxidation problems [5]. Therefore, it is vital to control wine aroma evolution during ageing to avoid important economic losses and image damage.

The major compounds responsible for oxidation aroma are acetaldehyde and Strecker aldehydes, mainly methional and phenylacetaldehyde [2,6,7]. However, a high proportion 
(70-95\%) of these compounds are present in wine in the form of odourless hydroxyalkylsulfonates [8]. On one hand, the acetaldehyde- $\mathrm{SO}_{2}$ adduct can be considered irreversible [9], on the other hand, the $\mathrm{SO}_{2}$-adducts formed with Strecker aldehydes have been shown to be reversible [10]. The free forms are released from the non-volatile adducts as the $\mathrm{SO}_{2}$ in the wine disappears, either by oxidation or by reaction with other species. In this way, Strecker aldehydes release due to equilibria shifts and thus could be sensory perceived. It has already been reported that the accumulation of aldehydes could be detrimental to wine quality [11], but to date there is no sensory study that determines the concentration of Strecker aldehydes able to decrease the aromatic quality of wines.

Taking into account the relevance of aldehydes and their reactivity, their removal might look interesting in wine as it is necessary in many areas such as pharmacy [12], industry [13], food [14] or biotechnology [15]. Such removal can be carried out in following different approaches such as distillation, gas stripping, pervaporation, solvent extraction, solid phase extraction [16], derivatisation [17] or precipitation and filtration from an organic solvent [15]. Nevertheless, for wine and with the intention of scaling the process of elimination of aldehydes to the winemaking process, it seems that the most appropriate methodology would be to use solid phase extraction with resins. Furthermore, if it were a reversible binding process it would allow the regeneration of the resins, as occurs with the Amberlite resin in the bisulphite form (IRA-SO $3 \mathrm{H}$ ) for the removal of 3-hydroxypropionaldehyde during the biotechnological conversion of glycerol [15].

Up to now, studies for the wine industry have been focused on the effect on organoleptic properties (i.e., colour improvement or haze prevention) of the use of ion exchange resins [18-21]. Currently the studies in the winery are aimed at the search for treatments that allow for the elimination of substances recognised as wine defects such as acetic acid or ethylphenols. From these ideas, the hypothesis arose of developing a methodology that could eliminate oxidation aldehydes present in wine through reactive polymers endowed with special functional groups [22] or classic-form and modified form ion-exchange resins [23]. Therefore, the objectives of this work are to study about the sensory impact derived from the release of Strecker aldehydes from hydroxyalkylsulfonate adducts during wine storage and to evaluate the potential capacity of different commercial resins to remove acetaldehyde and Strecker aldehydes from wine.

\section{Materials and Methods}

\subsection{Solvents and Chemicals}

Sodium metabisulfite $99 \%\left(\mathrm{Na}_{2} \mathrm{~S}_{2} \mathrm{O}_{5}\right)$, tartaric acid $(99 \%)$, glycerol $(99.5 \%), 1,2$-propanediol $(99.5 \%)$, sodium hydroxide $(98 \%)$, ortho phosphoric acid $(85 \%)$, hydrogen peroxide $3 \%$ stabilized $w / v$ VINIKIT, indicator 4,4 , mixed (methyl red-methylene blue) VINIKIT, sodium hydroxide $0.01 \mathrm{~mol} / \mathrm{L}$ VINIKIT were from Panreac (Barcelona, Spain). Dichloromethane, ethanol and methanol for gas chromatography analyses were purchased from Merk (Darmstadt, Germany). Glyoxal 40\% in water were supplied by Sigma-Aldrich (Madrid, Spain). Water was purified in a Milli-Q system from Millipore (Bedford, Germany). Chemical standards were supplied by Sigma-Aldrich, Fluka (Madrid, Spain), ChemService (West Chester, PA, USA) and Firmenich (Switzerland). Their purity is over $90 \%$ in all cases, and most of them are over $99 \%$. Specific details can be obtained from method references $[10,22,24]$.

\subsection{Evaluation of the Sensory Effect of the Release of Strecker Aldehydes from} Hydroxyalkylsulfonate Adducts

2.2.1. Wines for Sensory Analysis

Two wine models were generated mimicking: (a) a young wine and (b) an oaked wine. They were prepared by mixing a pool of common non-volatile and volatile wine components, detailed in Table 1, corresponding to the average concentration of aroma compounds found in a previous work [22]. 
Table 1. Wine models composition.

\begin{tabular}{|c|c|c|}
\hline \multirow{2}{*}{ Compounds } & \multicolumn{2}{|c|}{ Concentration $(\mathrm{mg} / \mathrm{L})$} \\
\hline & Young Wine & Oaked Wine \\
\hline Isoamyl alcohol & \multicolumn{2}{|c|}{180} \\
\hline$\beta$-Phenylethanol & \multicolumn{2}{|c|}{30} \\
\hline Acetic acid & \multicolumn{2}{|c|}{150} \\
\hline Ethyl acetate & \multicolumn{2}{|c|}{50} \\
\hline Hexanoic acid & \multicolumn{2}{|c|}{2.0} \\
\hline 3-Methylbutanoic acid & \multicolumn{2}{|c|}{0.30} \\
\hline 2,3-Butanedione & \multicolumn{2}{|c|}{0.40} \\
\hline Ethyl hexanoate & \multicolumn{2}{|c|}{1.0} \\
\hline Isoamyl acetate & \multicolumn{2}{|c|}{1.0} \\
\hline Ethyl 2- methylbutanoate & \multicolumn{2}{|c|}{0.12} \\
\hline Ethyl vanillate & \multicolumn{2}{|c|}{0.55} \\
\hline$\beta$-Damascenone & \multicolumn{2}{|c|}{0.0040} \\
\hline$\beta$-Ionone & \multicolumn{2}{|c|}{0.00030} \\
\hline$\gamma$-Nonalactone & \multicolumn{2}{|c|}{0.020} \\
\hline Guaiacol & 0.010 & 0.030 \\
\hline Vanillin & 0.070 & 0.17 \\
\hline Whisky lactone & 0 & 0.20 \\
\hline Eugenol & 0 & 0.020 \\
\hline 4-Hydroxy-2,5-dimethyl-3(2 H)- furanone & 0 & 0.10 \\
\hline Acetovanillone & 0 & 0.20 \\
\hline $\mathrm{pH}$ & \multicolumn{2}{|c|}{3.5} \\
\hline Glicerine (g/L) & \multicolumn{2}{|c|}{10} \\
\hline Quinine (mg/L) & \multicolumn{2}{|c|}{7.0} \\
\hline Arabic gum (mg/L) & \multicolumn{2}{|c|}{75} \\
\hline Ethanol (\%) & \multicolumn{2}{|c|}{12} \\
\hline Tannic acid (mg/L) & 50 & 100 \\
\hline Tartaric acid $(\mathrm{g} / \mathrm{L})$ & 5.0 & 4.0 \\
\hline
\end{tabular}

For studying the sensory relevance derived from the release of Strecker aldehydes from hydroxyalkylsulfonate adducts during wine storage for each of the two wine models, five aldehydes (isobutyraldehyde, 2-methylbutanal, 3-methylbutanal, methional and phenylacetaldehyde) were added at six concentration levels based on previous studies [8]. These levels are detailed in Table 2.

Table 2. Strecker aldehydes concentrations $(\mu \mathrm{g} / \mathrm{L})$ in wine models without sulphur dioxide.

\begin{tabular}{ccccccc}
\hline & Level 1 & Level 2 & Level 3 & Level 4 & Level 5 & Level 6 \\
\hline Isobutyraldehyde & 4.30 & 8.50 & 14.2 & 16.6 & 33.2 & 55.3 \\
2-Methylbutanal & 3.70 & 7.30 & 12.2 & 11.7 & 23.4 & 38.9 \\
3-Methylbutanal & 2.50 & 5.00 & 8.50 & 24.3 & 48.6 & 82.6 \\
Methional & 1.30 & 2.40 & 4.00 & 13.5 & 25.6 & 43.1 \\
Phenylacetaldehyde & 4.70 & 8.50 & 14.4 & 49.2 & 88.6 & 149 \\
\hline
\end{tabular}

These levels were selected in order to simulate the concentration of free aldehydes during different stages of wine ageing. Levels 4,5 and 6 ( 6 being the highest level, Table 2) mimic the maximum concentrations of aldehydes that can be released after the breakdown of the hydroxyalkylsulfonates by oxidation processes (in other words, maximal levels of aldehydes in the free forms). Differently, levels 1, 2, and 3 correspond approximately to 10 or $30 \%$ (depending on the compound) present in levels 4,5 and 6 . The rationale behind the selection of these two groups of concentration of the free aldehydes is that as stated in the mentioned reference, in a recently opened commercial wine with an adequate $\mathrm{SO}_{2}$ level for its preservation, the free forms present in the headspace are $30 \%$ of the total amount of isobutyraldehyde and 2-methylbutanal, whereas only the $10 \%$ for 3-methylbutanal, 
methional and phenylacetaldehyde, while the same wine under oxidative conditions, would present most of its aldehydes as free form. Accordingly, these six levels would correspond to three different wines with the same levels of total aldehydes: low category for levels 1 and 4, intermediate category for levels 2 and 5 and high category for levels 3 and 6 .

\subsubsection{Participants}

The sensory tasks were carried out by twenty participants (seven men and thirteen women, ranging from 25 to 63 years old, average $=37$ years old) with a long experience in wine aroma evaluation (oenologists and belonging to Laboratory for Flavour Analysis and Enology, LAAE staff) and considered wine experts according to Parr et al. [25].

\subsubsection{Procedure}

Twenty-mL wine samples were presented in dark ISO-approved wine glasses [26] labelled with 3-digit random codes and covered with plastic petri dishes according to a random arrangement presentation and different for each panellist.

Quality evaluation was carried out in two formal sessions. In the first session, each panellist evaluated six wine samples (one for each spiked level) for young wine samples. In the second session, participants repeated the task but with the six oaked wine samples.

In both sessions, participants were asked to exclusively smell the wine samples orthonasally (without tasting) from left to right. Then, they had to evaluate the perceived quality in a structured $10 \mathrm{~cm}$-scale (anchored with 3 categories: left-end with "low quality", in the middle "average quality" and right-end "high quality"). The quality score attributed to each wine sample was the distance in $\mathrm{cm}$ indicated by each panellist for each wine. Then, to identify the sensory drivers of perceived quality, each participant was requested to freely describe the high and low quality categories by indicating two or three attributes (avoiding hedonic terms) that apply to each quality categories.

\subsubsection{Data Analysis}

In order to assess how the breakdown of hydroxyalkylsulfonates adducts during wine storage affects the organoleptic quality of the wines, a two-way ANOVA (panellists as random and samples as fix factor) was performed with the panellist scores for quality scores, followed by Fischer post-hoc pairwise comparison (95\%) test.

The descriptors generated by the panel to describe each quality category were grouped in categories according to semantic similarities by three experienced researchers using a triangulation task $[27,28]$. For each wine, the number of panellists who chose a category was counted. This citation frequency (\%) was calculated as shown in Equation (1). Data analyses were carried out using XLSTAT (Addinsoft, version 2019).

$$
\text { Citation frequency }(\%)=\frac{\text { Number of panellists who chose a term }}{\text { Number of total panellist }} \times 100
$$

\subsection{Study of the Use of Resins to Remove Oxidation Aldehydes \\ 2.3.1. Wine Samples}

To investigate the effect of sulphur dioxide on the removal of aldehydes, the same white wine (Verdejo variety) was studied at two different sulphur dioxide concentration levels: (1) wine native $\mathrm{SO}_{2}$ concentration, (2) white wine spiked with sodium metabisulphite to increase the free $\mathrm{SO}_{2}$ to levels around $40 \mathrm{mg} / \mathrm{L}$.

\subsubsection{Resins}

Three types of resins were used:

- Nucleophilic Scavengers (non-regenerable): Siliabond from SiliCycle (Quebec, QC, Canada) and Ethylenediamino purchased from Sigma-Aldrich.

- Anionic Mixed Mode (regenerable): Oasis MAX from Waters (Mildford, MA, USA), Bond Elut Certify II from Varian (Palo Alto, CA, USA), Strata X-A and Strata X- 
AW from Phenomenex (Torrance, CA, USA). This type of resins required a previous conditioning step with methanol and vacuum drying under nitrogen stream.

- $\quad$ Anionic Pure Mode (regenerable): Dowex ${ }^{\mathrm{TM}} 1 \times 250-100$ and Amberlite ${ }^{\circledR}$ IRA 900 were purchased from Sigma-Aldrich.

Resin characteristics are shown in Table 3.

Table 3. Characteristics of the resins considered in the study.

\begin{tabular}{|c|c|c|c|c|c|c|c|c|c|}
\hline Type & Name & Code & $\begin{array}{l}\text { Type Spec- } \\
\text { ification }\end{array}$ & Matrix & $\begin{array}{l}\text { Functional } \\
\text { Group }\end{array}$ & $\begin{array}{c}\text { Particle } \\
\text { Size }(\mu \mathrm{m})\end{array}$ & $\begin{array}{c}\text { Pore } \\
\text { Size (A) }\end{array}$ & $\begin{array}{c}\text { Surface } \\
\text { Area }\left(\mathrm{m}^{2} / \mathrm{g}\right)\end{array}$ & Capacity \\
\hline \multirow{2}{*}{$\begin{array}{l}\text { Nucleophilic } \\
\text { Scavengers }\end{array}$} & Siliabond & SLB & Scavenger & Silica & & \multirow[t]{2}{*}{$40-63$} & $55-65$ & $480-550$ & $0.70 \mathrm{mmol} / \mathrm{g}$ \\
\hline & Ethylendiamino & ETDM & Scavenger & Silica & & & 60 & 500 & $1.40 \mathrm{mmol} / \mathrm{g}$ \\
\hline \multirow{4}{*}{$\begin{array}{c}\text { Anionic } \\
\text { Mixed Mode }\end{array}$} & Oasis MAX & MAX & $\begin{array}{l}\text { Polymeric } \\
+ \text { SAX }\end{array}$ & PVP-DVB & DMB-QA & 60 & $73-98$ & $727-889$ & $0.25 \mathrm{meq} / \mathrm{g}$ \\
\hline & $\begin{array}{l}\text { Bond Elut } \\
\text { Certify II }\end{array}$ & $\mathrm{BEC}$ & $\begin{array}{l}\text { Polymeric } \\
+ \text { SAX }\end{array}$ & $\mathrm{C} 8$ & TM-QA & $40-120$ & 60 & 500 & $0.85 \mathrm{meq} / \mathrm{g}$ \\
\hline & Strata X-A & SXA & $\begin{array}{l}\text { Polymeric } \\
+ \text { SAX }\end{array}$ & PS-DVB & DMB-QA & 33 & 85 & 800 & $0.30 \mathrm{meq} / \mathrm{g}$ \\
\hline & Strata X-AW & SXAW & $\begin{array}{l}\text { Polymeric } \\
+ \text { WAX }\end{array}$ & PS-DVB & $1,2-\mathrm{DA}$ & 33 & 85 & 800 & $0.60 \mathrm{meq} / \mathrm{g}$ \\
\hline \multirow{2}{*}{$\begin{array}{l}\text { Anionic Pure } \\
\text { Mode }\end{array}$} & $\begin{array}{l}\text { Dowex } 1 \times 2 \\
50-100\end{array}$ & DOW & SAX & $\begin{array}{l}\text { Styrene } \\
\text {-DVB }\end{array}$ & QA & 73-149 & - & - & $0.7 \mathrm{meq} / \mathrm{mL}$ \\
\hline & $\begin{array}{l}\text { Amberlite } \\
\text { IRA-900 }\end{array}$ & IRA & SAX & $\begin{array}{l}\text { Styrene } \\
\text {-DVB }\end{array}$ & QA & $650-820$ & - & - & $1 \mathrm{meq} / \mathrm{mL}$ \\
\hline
\end{tabular}

SAX: strong anion exchange; WAX: weak anion exchange; PVP: polyvinylpyrrolidone; DVB: divinylbenzene; C8: octyl group; PS: polystyrene; DMB: dimethyl butyl; QA: quaternary ammonium; TM: trimethyl; 1,2-DA: primary and secondary diamino.

\subsubsection{Experimental Procedure}

Eight resins were tested in duplicate for two samples: a commercial white wine and the same wine with a higher concentration of $\mathrm{SO}_{2}$. The controls of the experiment were the wines with the two levels of $\mathrm{SO}_{2}$ incubated under the same conditions, but without resins.

The addition of resins was carried out inside an oxygen free chamber from Jacomex (Dagneux, France). Thirty-six $60 \mathrm{~mL}$ tightly screw capped clear glass vials supplied by WIT-France (Bordeaux, France), containing $10 \mathrm{~g} / \mathrm{L}$ of the corresponding resin were used. The tubes were filled up completely with wine, and were carefully closed, avoiding any headspace. The tubes were incubated in a thermostatic bath Grant OLS23 with orbital shaking $(130 \mathrm{rpm})$ at $25^{\circ} \mathrm{C}$. After $24 \mathrm{~h}$, the tubes were introduced back into the anoxic chamber in order to decant the resins and then, the wines were analysed.

\subsubsection{Chemical Analysis}

Oenological conventional parameters of colour, total polyphenol index (TPI), $\mathrm{pH}$, total acidity, free sulphur dioxide, total sulphur dioxide, total acetaldehyde and total Strecker aldehydes were determined at time zero and after the treatment with resins.

Results were processed by means of analysis of variance (ANOVA), whereas mean values were compared by Fischer's test (XLSTAT). The value of $p \leq 0.05$ was considered statistically significant, and alphabetical letters were used along means in the tables.

\section{Conventional Oenological Parameters}

The total acidity was determined by acid-base volumetric titration measuring the end of the titration with a $\mathrm{pH}$ meter up to $\mathrm{pH} 7$ according to the Organization of Vine and Wine (OIV) [29].

The $\mathrm{pH}$ was determined by potentiometry according to OIV practices [30].

For free and total sulphur dioxide determination, the aspiration/titration method recommended by the OIV was used [31]. 
Spectrophotometric Measurements

For colour determination, absorbances at wavelengths 420,520 and $620 \mathrm{~nm}$ of undiluted wine samples were measured using glass cells with optical paths of 1,2 or $5 \mathrm{~mm}$, taking the measurement which provided absorbance readings between 0.3 and 0.7 as recommended by the OIV [32]. TPI was determined as absorbance at $280 \mathrm{~nm}$ as described by Ribéreau-Gayon et al. [33]. All the absorbance measurements were recorded using an UV-vis spectrophotometer UV-17000 Pharma Spec from Shimadzu (Kyoto, Japan).

Total Acetaldehyde Determination

Total acetaldehyde was determined by gas chromatography with flame ionization detection (GC-FID) by injection of $1 \mu \mathrm{L}$ of wine sample spiked with 2-butanol as internal standard. The methodology is based on breaking the adducts directly in the injector port. A GC 8000 series from Fisons Instrument (Ipswich, UK) with a DB-WAX $(30 \mathrm{~m} \times 0.53 \mathrm{~mm}$ of i.d. $\times 2 \mu \mathrm{m}$ ) capillary column from J\&W Scientific (Agilent Technologies, Santa Clara, CA, USA) were used. The injector was kept at $250^{\circ} \mathrm{C}$ and the split ratio was 1:4. Hydrogen was used as carried gas and the pressure was kept at $27.5 \mathrm{kPa}$. The temperature program was $50{ }^{\circ} \mathrm{C}$ for $5 \mathrm{~min}$ and then raised to $220^{\circ} \mathrm{C}$ in $10 \mathrm{~min}$. The FID temperature was $250{ }^{\circ} \mathrm{C}$. The calibration was obtained by the analysis of synthetic wines $(5 \mathrm{~g} / \mathrm{L}$ tartaric acid, $12 \%$ ethanol, $1.5 \%$ propane-1,2-diol, $10 \mathrm{~g} / \mathrm{L}$ glycerin, $\mathrm{pH} 3.5$ ) containing known amounts of acetaldehyde and plotting the corresponding peak areas (normalized by the internal standard) versus the mass of acetaldehyde. Other validation parameters are detailed elsewhere [24].

\section{Total Strecker Aldehydes Determination}

Total Strecker aldehydes content was determined as described by Bueno et al. [10]. In summary, vials were prepared inside an oxygen free chamber, pouring $10 \mathrm{~mL}$ of wine sample into a $20 \mathrm{~mL}$ vial. Then samples were spiked with methyl 2-methylbutyrate $(187 \mu \mathrm{g} / \mathrm{L})$ as internal standard and $6 \mathrm{~g} / \mathrm{L}$ of glyoxal. Vials were then closed and incubated at $50{ }^{\circ} \mathrm{C}$ for $6 \mathrm{~h}$ for ensuring that carbonyl-bisulphite complexes had been broken. Total isobutyraldehyde, 2-methylbutanal, 3-methylbutanal, methional and phenylacetaldehyde were measured by headspace-solid phase microextraction followed by gas chromatographymass spectrometry (HS-SPME-GC-MS) using a polydimethylsiloxane/divinylbenzene (PDMS/DVB) fibre from Supelco (Madrid, Spain).

\section{Data Analysis}

Results were analysed by analysis of variance (ANOVA), and for significant effects post-hoc Fischer's test was calculated (XLSTAT). The value of $p \leq 0.05$ was considered statistically significant, and alphabetical letters were used along means in the tables to indicate significant differences.

\section{Results and Discussion}

In the present work, the effect of the presence of Strecker aldehydes (released as a consequence of the depletion of sulphur dioxide) on the quality perceived by a group of Spanish technical experts in two different wine contexts has been evaluated. Further, the effect of different commercial resins on the elimination of these oxidation-related aldehydes has been tested.

\subsection{Sensory Significance Derived from the Release of Strecker Aldehydes from Hydroxyalkylsulfonate Adducts}

Strecker aldehydes in wine can be found in their free form, which is volatile and can be orthonasally perceived, or in their adduct form with $\mathrm{SO}_{2}$ (hydroxyalkylsulfonate), which is non-volatile and cannot be sensory perceived. In fact, it has been reported that non-oxidised commercial wines contain a pool of powerful oxidation-related Strecker aldehydes (from 33 to $96 \%$ ) that are released back into their free volatile form when free 
$\mathrm{SO}_{2}$ disappears [8]. However, the concentration of Strecker aldehydes that are detrimental to wine aroma quality has not been studied yet.

The quality scores given by the panel of experts for the six samples in each of the contexts indicates that the quality varies significantly $(p<0.001)$ with the level of aldehydes in both contexts. As can be seen in Figure 1, the increase in the concentration of aldehydes (from level 1 to level 6) causes a significant decrease in the perceived aroma quality in both contexts. In young wines, the release of Strecker aldehydes decreases orthonasal quality by between $27-40 \%$ and in oaked wines by $36-47 \%$ in both cases for the three aldehyde categories.
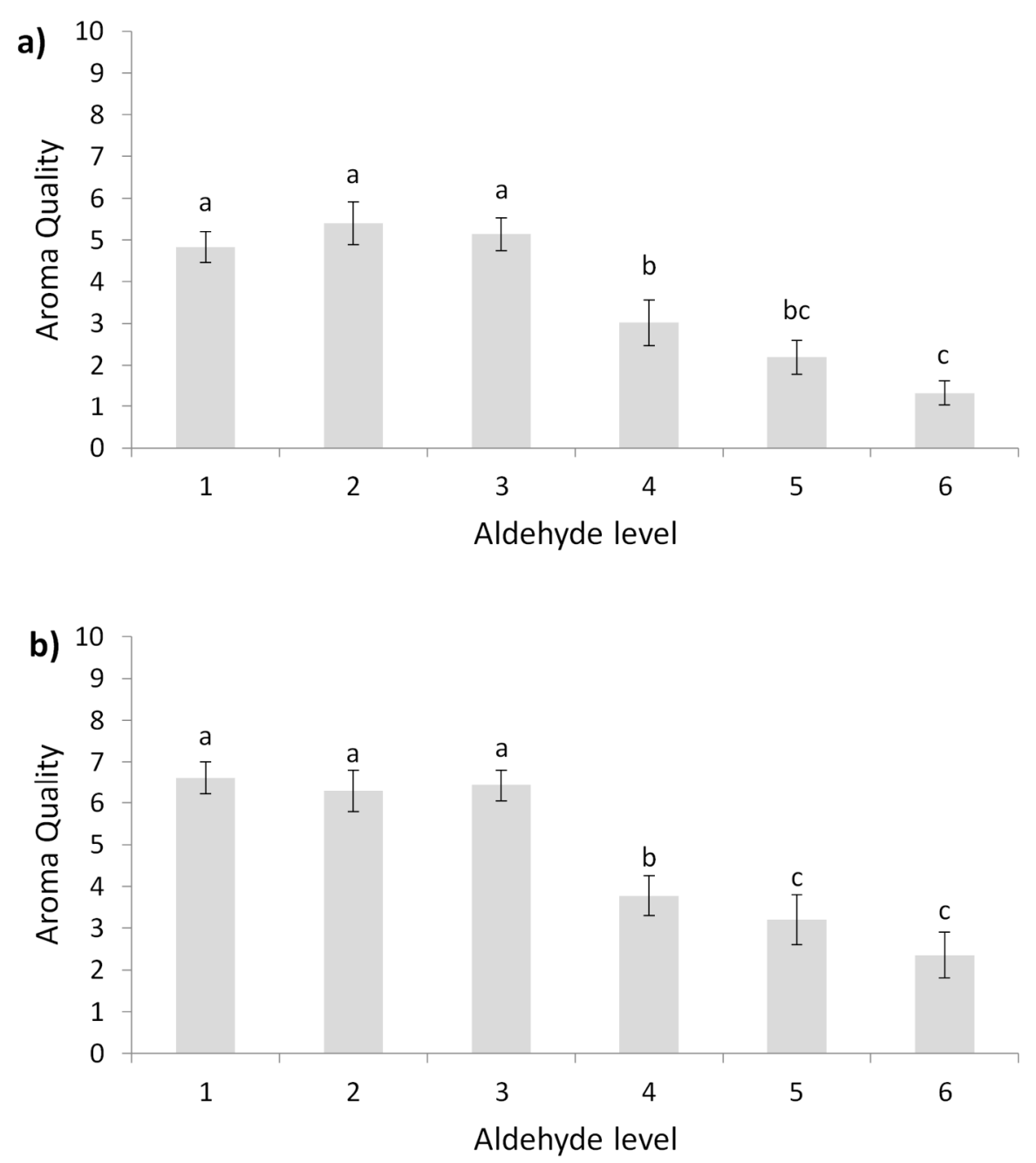

Figure 1. Average aroma quality for different levels of aldehydes. (a) Young wine model (b) Oaked wine model. Different letters within the same graphic indicate significant differences $(p \leq 0.05)$. Error bars are calculated as $\mathrm{sd} / \mathrm{n}^{0.5}$; sd: standard deviation; $n$ : number of panellists.

As can be seen in Figure 1, in both wine models, the maximum drop in quality is found from level 4. This implies that at the beginning of the shelf life of a wine (i.e., low levels of free aldehydes: levels 1-3), the initial concentration of free aldehydes regardless of the total amount of aldehydes (low, intermediate or high category) is at levels low enough to be hardly sensory perceived resulting in an absence of significant decrease in wine quality perception, according to the panel of wine experts. On the contrary, the ageing process (levels 4-6), with its implicit loss of $\mathrm{SO}_{2}$, causes the amount of free aldehydes to increase and thus to be sensory perceived resulting in a significant wine quality decrease.

Table 4 shows the decrease in quality scores due to the release of the free forms of aldehydes for similar theoretical levels of total aldehydes (e.g., high category: average 
quality score for the level 6 minus level $3=-3.8$ for the young wine). As it was expected, the panel of experts punishes the increment more in aldehyde concentration due to the simulation of the release of aldehydes from the breakdown of the aldehyde- $\mathrm{SO}_{2}$ adducts in wines with high amounts of total aldehydes (level 3 and level 6) compared to wines with low amounts (level 1 and level 4) (in both contexts). However, comparing the same aldehyde category in both wine models, quality depreciation was only significant for the lower aldehyde concentration $(p \leq 0.001)$, being more pronounced for oaked wines.

Table 4. Aroma quality differences due to the release of bound aldehydes.

\begin{tabular}{|c|c|c|c|}
\hline Differences Due to the Release of Bound Aldehydes & Young Wine & Oaked Wine & $p$-Value (Context) \\
\hline High category (level 6-level 3) & $-3.8^{\mathrm{a}}$ & $-4.1^{\mathrm{a}}$ & 0.077 \\
\hline Intermediate category (level 5-level 2) & $-3.2^{b}$ & $-3.1^{b}$ & 0.206 \\
\hline Low category (level 4-level 1) & $-1.8^{\mathrm{cB}}$ & $-2.8^{\mathrm{bA}}$ & $<0.001$ \\
\hline$p$-value (category) & $<0.001$ & $<0.001$ & \\
\hline
\end{tabular}

a-c: different superscripts within the same column denote statistical differences $(p \leq 0.05)$ between different aldehyde category for the same wine context. A-B: different superscripts in the same row denote statistical differences $(p \leq 0.05)$ between wine context for the same aldehyde category.

Figure 2 shows the spider graphs representing the citation frequencies of the attributes related to high quality or low quality in each wine context exemplars. In concordance with these frequencies, young wines with high quality would be mainly related to fruity aromas (Figure 2a), while low quality would be driven by descriptors such as cooked vegetables and oxidation-related attributes (Figure 2c).

This result suggests that the release of aldehydes during the oxidation of a young wine produces a masking effect on the fruity character of young wines, and the appearance of aromas related to cooked, oxidised vegetables, raisins, honey, alcoholic/fusel, stale apple and olive broth. For oaked wines, high quality seems to be represented by the presence of woody aromas (Figure $2 b$ ), while low quality wines would be related to a predominant note of cooked vegetables (Figure 2c). This seems to indicate that the increase in the concentration of aldehydes in their free forms produces a masking effect of the woody notes and the appearance of the negative attributes of aldehydes: cooked vegetables, honey, stale apple, dirty and oxidised.

It should be noted that the overripe fruit descriptor appears to be a descriptor linked to both high and low quality. This result suggests that there are two quality prototypes among the group of experts: $80 \%$ of them noted that this descriptor is a cue influencing positively wine quality against a $20 \%$ that find this descriptor to be involved in the detriment of wine quality. This is not an isolated example, Saenz-Navajas et al. observed that the same attribute could be related to high or low quality [34]. For high quality wine, this attribute can be tolerated by experts, whereas for low quality wines constitutes a rather negative feature.

Concerning the sensory results obtained, it is demonstrated that an appreciable sensory change occurs when the Strecker aldehydes from the hydroxyalkylsulfonates are released by depletion of $\mathrm{SO}_{2}$ due to the reversibility of this union, even without the need to form any de novo aldehyde molecule from its amino acid (Strecker reaction) or alcohol precursors (direct peroxidation). In addition, comparing with works previously published by our research group, it has been found that more than $75 \%$ of recently opened commercial wines contain total levels of Strecker aldehydes higher than those of level 4 (Table 2) [8,24]. 
a)

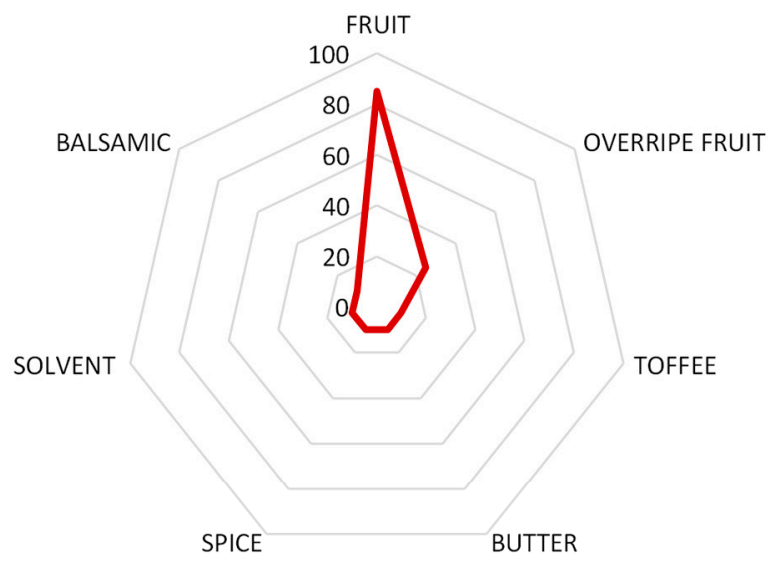

b)

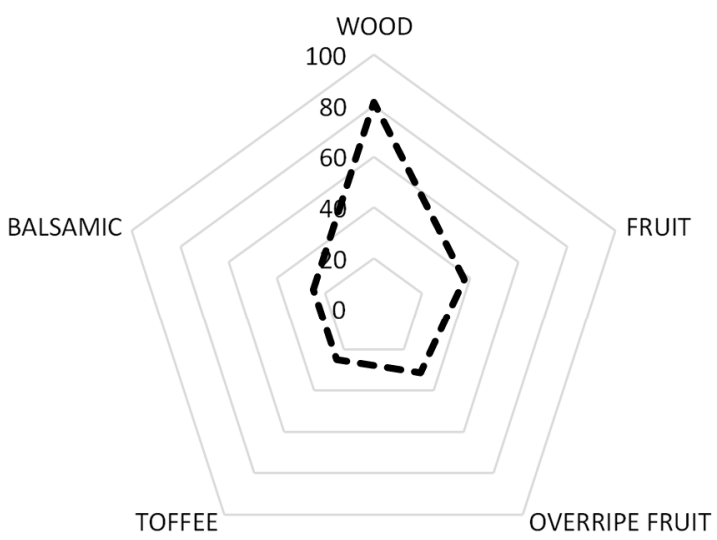

c)

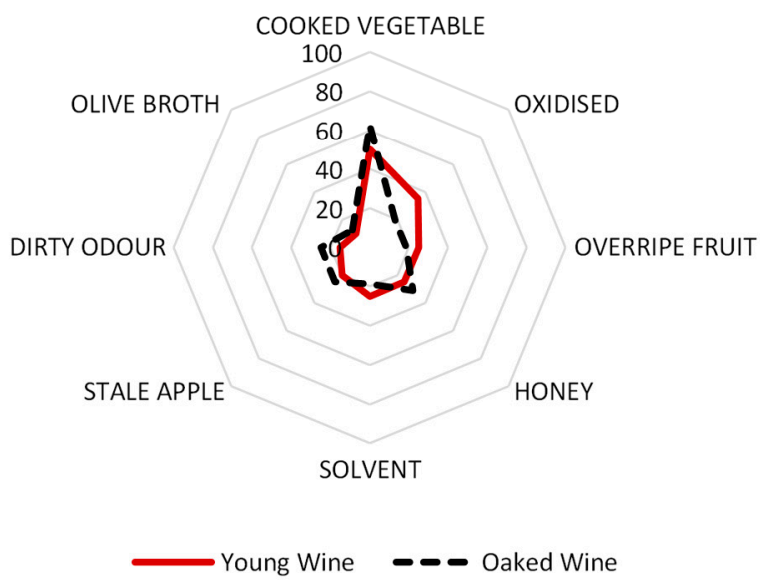

Figure 2. Citation frequency percentage of attributes related to (a) young wine with high aroma quality, (b) oaked wine with high aroma quality and (c) young and oaked wines with low aroma quality.

3.2. Potential Ability of Different Commercial Resins to Eliminate Aldehydes Responsible for the Oxidation Notes in Wine

The sensory suppression of acetaldehyde by adding sulphur dioxide has been addressed in a previous work [35]. This $\mathrm{SO}_{2}$ addition binds acetaldehyde practically in a reversible way, due to the high adduct formation constant. However, although this $\mathrm{SO}_{2}$ addition solves the problem for this compound, it has been exposed in this paper that it would mask and delay a problem with Strecker's aldehydes. Given the negative influence 
that all these aldehydes have on the orthonasal quality of wines at commonly found concentrations, it seems pertinent to study the potential capacity of different commercial resins to eliminate them, including acetaldehyde.

The removal evaluation has been carried out with a commercial white wine and the same wine spiked with potassium metabisulfite to test two different concentrations of $\mathrm{SO}_{2}$ in the wine. Two types of resins were tested: (1) nucleophilic scavengers that remove free aldehydes and force a shift of the $\mathrm{SO}_{2}$-aldehyde equilibrium (Figure 3), and (2) anion exchange that remove the hydroxyalkylsulfonate adducts. Within the latter type, pure anion exchange resins based on styrene-divinylbenzene with quaternary ammonium as a functional group and mixed mode anion exchange resins with different matrices and functional groups were used (see Table 3).

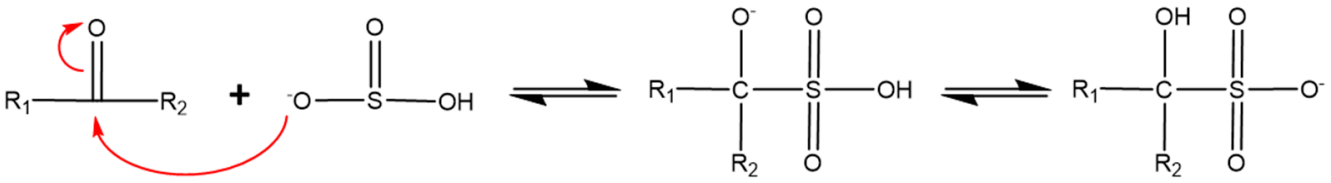

Figure 3. Hydroalkylsulfonate adduct formation equilibrium.

Table 5 shows the total concentrations of the six aldehydes in the control wines and the wines treated with each resin. The values provided by the quantitative methods are those of total aldehydes, for this reason and despite the fact that $\mathrm{SO}_{2}$ content is different, the values obtained for both controls are the same (there are no significant differences).

Table 5. Total Strecker aldehydes $(\mu \mathrm{g} / \mathrm{L})$ and acetaldehyde $(\mathrm{mg} / \mathrm{L})$ concentrations after $24 \mathrm{~h}$ at $25{ }^{\circ} \mathrm{C}$ in contact with the resins.

\begin{tabular}{|c|c|c|c|c|c|c|c|c|c|c|c|c|c|}
\hline \multirow{2}{*}{$\begin{array}{l}\text { Levels } \\
\text { of } \mathrm{SO}_{2}\end{array}$} & & \multicolumn{2}{|c|}{ Isobutyraldehyde } & \multicolumn{2}{|c|}{$\begin{array}{c}2- \\
\text { Methylbutanal }\end{array}$} & \multicolumn{2}{|c|}{$\begin{array}{c}\text { 3- } \\
\text { Methylbutanal }\end{array}$} & \multicolumn{2}{|c|}{ Methional } & \multicolumn{2}{|c|}{ Phenylacetaldehyde } & \multicolumn{2}{|c|}{ Acetaldehyde } \\
\hline & & Mean & $\begin{array}{l}\text { RSD } \\
(\%)\end{array}$ & Mean & $\begin{array}{c}\text { RSD } \\
(\%)\end{array}$ & Mean & $\begin{array}{c}\text { RSD } \\
(\%)\end{array}$ & Mean & $\begin{array}{l}\text { RSD } \\
(\%)\end{array}$ & Mean & $\begin{array}{c}\text { RSD } \\
(\%)\end{array}$ & Mean & $\begin{array}{c}\text { RSD } \\
(\%)\end{array}$ \\
\hline \multirow{9}{*}{$\begin{array}{c}\text { Free } \mathrm{SO}_{2} \\
12.8 \mathrm{mg} / \mathrm{L} \\
\text { Total } \mathrm{SO}_{2} \\
142.8 \mathrm{mg} / \mathrm{L}\end{array}$} & Control & $10.6^{\mathrm{ab}}$ & 6.2 & $4.85^{\mathrm{a}}$ & 9.4 & $50.5^{\mathrm{a}}$ & 4.2 & \multirow{2}{*}{$\begin{array}{c}9.80^{\mathrm{a}} \\
7.11 \\
\text { bcd }\end{array}$} & 5.5 & $31.6^{b c}$ & 1.2 & $49.7^{a b}$ & 1.8 \\
\hline & SLB & $5.40^{\mathrm{d}}$ & 46 & $1.22 \mathrm{e}$ & 57 & $33.9^{\text {ef }}$ & 14 & & 15 & $415^{\mathrm{a}}$ & 1.6 & $46.0^{b c}$ & 11 \\
\hline & ETDM & $9.80^{b c}$ & 4.7 & $3.97^{\mathrm{ab}}$ & 0.7 & $49.5^{\mathrm{ab}}$ & 1.8 & $10.1^{\mathrm{a}}$ & 4.7 & $35.9^{b}$ & 2.7 & $51.5^{\mathrm{a}}$ & 2.3 \\
\hline & MAX & $9.40^{b c}$ & 7.6 & $3.68^{b c}$ & 7.9 & $35.5^{\text {def }}$ & 12 & $5.65^{\mathrm{e}}$ & 18 & $<\mathrm{LQ}^{\mathrm{e}}$ & - & $47.7^{\mathrm{a}}$ & 0.1 \\
\hline & $\mathrm{BEC}$ & $9.50^{b c}$ & 1.9 & $4.00^{\mathrm{ab}}$ & 8.1 & $48.0^{\mathrm{ab}}$ & 2.0 & $7.87 \mathrm{bc}$ & 1.5 & $21.1^{\mathrm{d}}$ & 14 & $51.0^{\mathrm{abc}}$ & 2.6 \\
\hline & SXA & $8.80^{b c}$ & 11 & $2.53^{\mathrm{d}}$ & 14 & $35.8^{\text {de }}$ & 7.6 & $6.19 \mathrm{de}$ & 8.3 & $<\mathrm{LQ}^{\mathrm{e}}$ & - & $44.8^{\mathrm{cd}}$ & 3.1 \\
\hline & SXAW & $12.5^{\mathrm{a}}$ & 8.8 & $\begin{array}{l}3.15 \\
\text { bcd }\end{array}$ & 22 & $30.1^{\mathrm{f}}$ & 3.0 & $6.79^{\mathrm{cde}}$ & 0.9 & $<\mathrm{LQ}^{\mathrm{e}}$ & - & $43.5^{\mathrm{cd}}$ & 0.9 \\
\hline & DOW & $8.30^{\mathrm{c}}$ & 4.1 & $2.91^{\mathrm{cd}}$ & 5.7 & $40.0^{\mathrm{cd}}$ & 0.1 & $6.83^{\text {cde }}$ & 3.7 & $25.5^{\mathrm{cd}}$ & 2.4 & $41.0^{\mathrm{d}}$ & 1.0 \\
\hline & IRA & $8.90^{b c}$ & 0.6 & $3.44^{b c}$ & 6.0 & $44.6^{\mathrm{bc}}$ & 3.8 & $8.38^{b}$ & 5.0 & $25.8^{\mathrm{cd}}$ & 5.7 & $44.0^{\mathrm{cd}}$ & 1.1 \\
\hline$p$-value (nat & ve $\mathrm{SO}_{2}$ ) & 0.005 & & $<0.001$ & & $<0.001$ & & $<0.001$ & & $<0.001$ & & 0.004 & \\
\hline \multirow{9}{*}{$\begin{array}{c}\text { Free } \mathrm{SO}_{2} \\
36.8 \mathrm{mg} / \mathrm{L} \\
\text { Total SO} \\
172.8 \mathrm{mg} / \mathrm{L}\end{array}$} & Control & $10.0^{\mathrm{BC}}$ & 2.3 & $4.71^{\mathrm{A}}$ & 14 & $47.5^{\mathrm{A}}$ & 2.2 & $9.21^{\mathrm{B}}$ & 1.7 & $28.5^{C}$ & 0.5 & $48.5^{\mathrm{A}}$ & 6.5 \\
\hline & SLB & $4.80^{\mathrm{D}}$ & 50 & $1.31^{\mathrm{C}}$ & 57 & $34.8^{\mathrm{C}}$ & 26 & $7.60^{C}$ & 6.0 & $363^{A}$ & 1.5 & $40.1^{\mathrm{C}}$ & 8.3 \\
\hline & ETDM & $10.8^{\mathrm{AB}}$ & 0.8 & $4.74^{\mathrm{A}}$ & 0.4 & $47.2^{\mathrm{AB}}$ & 1.4 & $11.2^{\mathrm{A}}$ & 7.9 & $41.6^{\mathrm{B}}$ & 3.1 & $47.5^{\mathrm{A}}$ & 3.6 \\
\hline & MAX & $9.30^{\mathrm{BC}}$ & 4.5 & $4.67^{\mathrm{A}}$ & 1.5 & $39.4^{\mathrm{BC}}$ & 4.0 & $6.40^{\mathrm{CD}}$ & 2.3 & $<\mathrm{LQ}^{\mathrm{E}}$ & - & $45.7^{\mathrm{A}}$ & 0.3 \\
\hline & BEC & $\begin{array}{l}10.1 \\
\mathrm{ABC}\end{array}$ & 1.3 & $4.63^{\mathrm{A}}$ & 12 & $47.1^{\mathrm{AB}}$ & 1.1 & $7.50^{\mathrm{C}}$ & 1.5 & $22.9^{\mathrm{CD}}$ & 3.1 & $45.3^{\mathrm{A}}$ & 1.7 \\
\hline & SXA & $8.90^{B C}$ & 8.6 & $3.32^{\mathrm{B}}$ & 8.8 & $32.8^{C D}$ & 11 & $6.10^{\mathrm{D}}$ & 23 & $<\mathrm{LQ}^{\mathrm{EF}}$ & - & $46.9^{\mathrm{A}}$ & 2.9 \\
\hline & SXAW & $12.3^{\mathrm{A}}$ & 4.3 & $3.80 \mathrm{AB}$ & 0.1 & $25.5^{\mathrm{D}}$ & 5.4 & $5.90^{\mathrm{D}}$ & 7.7 & $<\widehat{\mathrm{LD}}^{\mathrm{F}}$ & - & $44.4^{\mathrm{AB}}$ & 3.9 \\
\hline & DOW & $8.50^{\mathrm{C}}$ & 4.7 & $3.91 \mathrm{AB}$ & 4.2 & $36.7^{\mathrm{C}}$ & 1.7 & $6.90^{C D}$ & 2.4 & $19.6^{\mathrm{D}}$ & 15 & $38.8^{\mathrm{C}}$ & 1.2 \\
\hline & IRA & $9.80^{\mathrm{BC}}$ & 13 & $4.67^{\mathrm{A}}$ & 6.9 & $\begin{array}{l}40.4 \\
\mathrm{ABC}\end{array}$ & 7.6 & $7.00^{C D}$ & 4.7 & $19.2^{\mathrm{D}}$ & 19 & $40.6^{\mathrm{BC}}$ & 2.0 \\
\hline \multicolumn{2}{|c|}{$\begin{array}{c}p \text {-value (high } \mathrm{SO}_{2} \\
\text { level) }\end{array}$} & 0.002 & & $<0.001$ & & 0.002 & & $<0.001$ & & $<0.001$ & \multicolumn{3}{|c|}{0.003} \\
\hline
\end{tabular}

RSD: relative standard deviation; LD: detection limit of phenylacetaldehyde $(3 \mu \mathrm{g} / \mathrm{L})$; LQ: quantification limit of phenylacetaldehyde $(10 \mu \mathrm{g} / \mathrm{L})$. a-f: different superscripts within the same column denote statistical differences $(p \leq 0.05)$ between different resin treatments for wine with native $\mathrm{SO}_{2}$ content. A-F: different superscripts within the same column denote statistical differences $(p \leq 0.05)$ between different resin treatments for wine with high $\mathrm{SO}_{2}$ level. 
In general, the reproducibility of the elimination process was satisfactory. Most of the relative standard deviations (RSD) were less than $15 \%$, with the exception of SLB resin for the removal of the more volatile aldehydes (isobutyraldehyde, 2-methylbutanal and 3-methylbutanal) at both levels of $\mathrm{SO}_{2}$.

The removal percentages obtained were relevant. For isobutyraldehyde, they reached $22 \%$, except for SXAW resin where a significant increase $(p=0.03)$ was observed at higher levels of $\mathrm{SO}_{2}$. For 2-methylbutanal, the decrease ranged from 0.2 to $47 \%$. Nearly all the resins showed significant reductions in their amounts of 3-methylbutanal and methional compared to the control for both $\mathrm{SO}_{2}$ levels (Table 5) achieving elimination percentages up to $46 \%$ and $43 \%$, respectively.

Phenylacetaldehyde increased its concentration after $24 \mathrm{~h}$ in contact with the scavengers. This type of resin cannot remove phenylacetaldehyde at all, and at the end of the process the concentration of aldehyde has increased. Two possible options are considered to explain this fact:

(a) Some nucleophile that is present in the resin reaches to break stable adducts (adducts that the method of determination of total aldehydes using glyoxal is not able to break).

(b) Another possibility will be that some trace contaminant, such as the amino acid phenylalanine, has been transferred from the resin and if there are $\alpha$-dicarbonyls present in the medium, the Strecker reaction has occurred.

Notwithstanding, phenylacetaldehyde showed good elimination results using mixed mode resins such as MAX, SXA and SXAW (Table 5). These resins achieved removal percentages higher than $68 \%$ for the two sulphur dioxide levels. These types of resins have aromatic rings in their structures that would stabilize with the phenylacetaldehyde reaction. In addition, they have a large pore size (73-98 A) and specific surface area $\left(727-889 \mathrm{~m}^{2} / \mathrm{g}\right)$, making the reaction with phenylacetaldehyde, which is a voluminous molecule, more favourable. However, pure anion exchange resins exhibit less removal for this compound.

Acetaldehyde exhibited removals up to $20 \%$ with DOW pure anion exchange resin. These removal percentages are very high if we compare with previous works where the concentration of total acetaldehyde did not change significantly, when an ionic exchange in column was applied to a wine of the Airén variety in order to improve its colour [36].

Briefly, the resins that are repeated more times with significant differences, with respect to the control for all aldehydes (Table 5), are principally DOW and SXA for both $\mathrm{SO}_{2}$ levels.

Furthermore, by increasing the $\mathrm{SO}_{2}$ level, the formation of hydroxyalkylsulfonates would be favoured and, in principle, a greater reducing effect of the pure and mixed mode ion exchange resins would be expected. Nevertheless, data show that only the removal of acetaldehyde has been significantly favoured with the pure ion exchange resins DOW $(p=0.017)$ and IRA $(p=0.018)$. In the case of phenylacetaldehyde, a greater reduction was also found due to the effect of sulphur dioxide in the DOW resin $(p=0.05)$.

The existence of significant effects only for these two aldehydes may be due to the fact that acetaldehyde is the most reactive compound with $\mathrm{SO}_{2}$ [9], and although the formation constant of the adduct with methional is greater than that of phenylacetaldehyde (50 $\times 10^{3}$ versus $\left.17 \times 10^{3}[10]\right)$, the phenylacetaldehyde adduct could be stabilized on the aromatic ring structures of mixed resins.

\subsection{Effects of Resin Treatment on Other Wine Parameters}

To assess other effects produced by the treatments with resins, free $\mathrm{SO}_{2}$, total $\mathrm{SO}_{2}, \mathrm{pH}$, total acidity, TPI and colour of all the samples were analysed before and after the treatment (Table 6). 
Table 6. Removal percentage of $\mathrm{SO}_{2}$, colour and total polyphenol index (TPI) after $24 \mathrm{~h}$ of treatment with resins. Total acidity, TA (g/L tartaric acid) and $\mathrm{pH}$ after $24 \mathrm{~h}$.

\begin{tabular}{|c|c|c|c|c|c|c|c|c|c|c|c|c|}
\hline & \multicolumn{8}{|c|}{ Removal Percentage } & \multicolumn{4}{|c|}{ Final Data } \\
\hline & \multicolumn{2}{|c|}{$\mathrm{SO}_{2}$ Free } & \multicolumn{2}{|c|}{$\mathrm{SO}_{2}$ Total } & \multicolumn{2}{|c|}{ TPI } & \multicolumn{2}{|c|}{ Colour } & \multicolumn{2}{|c|}{ TA } & \multicolumn{2}{|c|}{ pH } \\
\hline & $\mathrm{T} 1$ & T2 & T1 & $\mathrm{T} 2$ & T1 & $\mathrm{T} 2$ & T1 & $\mathrm{T} 2$ & T1 & T2 & T1 & $\mathbf{T} 2$ \\
\hline Control & & & & & & & & & 5.4 & 5.4 & 3.2 & 3.1 \\
\hline SLB & -16 & -3.5 & 9.0 & 31 & 0.14 & -4.7 & 29 & 32 & 5.3 & 5.4 & 3.2 & 3.2 \\
\hline ETDM & 0.10 & 13 & 17 & 23 & 12 & 10 & 16 & 20 & 3.5 & 3.6 & 3.7 & 3.8 \\
\hline MAX & 11 & 37 & 22 & 27 & 45 & 42 & 76 & 75 & 5.3 & 5.4 & 3.2 & 3.1 \\
\hline BEC & 6.0 & 11 & 27 & 16 & 8.6 & 3.8 & 24 & 20 & 5.6 & 5.6 & 3.2 & 3.1 \\
\hline SXA & 13 & 19 & 38 & 34 & 48 & 44 & 85 & 83 & 5.2 & 5.3 & 3.2 & 3.1 \\
\hline SXAW & 0.40 & 18 & 34 & 29 & 31 & 23 & 72 & 75 & 4.5 & 4.6 & 3.6 & 3.4 \\
\hline DOW & 0.30 & 30 & 45 & 52 & 39 & 38 & 68 & 68 & 5.1 & 5.1 & 3.1 & 3.0 \\
\hline IRA & 13 & 35 & 28 & 57 & 44 & 45 & 63 & 64 & 5.2 & 5.1 & 3.0 & 3.0 \\
\hline
\end{tabular}

T1: test with the wine initial $\mathrm{SO}_{2}$ level $\left(\right.$ Free $\mathrm{SO}_{2}: 12.8 \mathrm{mg} / \mathrm{L}$. Total $\left.\mathrm{SO}_{2}: 142.8 \mathrm{mg} / \mathrm{L}\right)$. T2: test with wine spiked with $\mathrm{SO}_{2}\left(\right.$ Free $\mathrm{SO}_{2}: 36.8 \mathrm{mg} / \mathrm{L}$. Total $\left.\mathrm{SO}_{2}: 172.8 \mathrm{mg} / \mathrm{L}\right)$

For the SLB scavenger, a higher concentration of free sulphur dioxide (16\%) is obtained after incubation, showing that the process has worked properly, and the equilibrium has been displaced. In the test with the same wine spiked with $\mathrm{SO}_{2}$, only a $3 \%$ increase of free $\mathrm{SO}_{2}$ was found, which may indicate that the breakdown of the hydroxyalkylsulfonate adducts due to the removal of the aldehyde is not favourable at high adduct concentrations (see Table 6). The other scavenger, ETDM, seems to have been less effective if this parameter is taken into account, however, almost the same difference is again observed between the wine with the native content of $\mathrm{SO}_{2}$ or the one with higher amount.

Regarding ion exchange resins, the ones that react directly with the adduct, it was expected that the free and total sulphur dioxide would decrease as the process progressed. Indeed, this is effectively what has been obtained and is reflected in Table 6. Having an initial wine with a higher sulphur dioxide content increases the percentage of $\mathrm{SO}_{2}$ removal due to the treatment, especially with the pure ion exchange resins DOW and IRA.

Regarding TPI and colour, the resins behaved in the same way regardless of the level of $\mathrm{SO}_{2}$ in the initial wine. The decrease in these parameters may mainly be due to the elimination of catechins and hydroxycinnamic acids [36]. Hermonsín et al. established in their work the selection of ion exchange resins, a maximum colour elimination criterion of 35\% in order not to compromise the rest of the sensory properties [36]. As can be seen in Table 6, only the scavengers would fulfil this premise, obtaining a marked decrease in colour (higher than 63\%) for the rest of the resins, except for BEC.

Regarding the $\mathrm{pH}$ and total acidity, only the treatment with ETDM and SXAW resins provided a notable variation. In these two cases, the $\mathrm{pH}$ increased and the total acidity decreased, which is totally undesirable at an oenological level, since it compromises the microbial stability of the wine.

It must be considered that the concentration of phenylacetaldehyde increased after the treatment with scavenger resins. Moreover, one of the two resins of this type sharply decreased the total acidity of the wine. Therefore, the use of scavengers in this context can be ruled out. Thus, reaching a compromise, it can be concluded that the resins with the best behaviour are the mixed ion exchange SXA, both for the elimination of aldehydes, except isobutyraldehyde, and for maintaining the $\mathrm{pH}$ and total acidity to a great extent, closely followed by MAX resin. However, the colour decrease is greater than $75 \%$ in both cases. Perhaps by using a lower dose than the one studied in this work $(10 \mathrm{~g} / \mathrm{L})$, the process would be more viable from a sensory and economic point of view.

\section{Conclusions}

This work has revealed that in the context of young wine and oaked wine, the release of aldehydes due to the breakdown of the aldehyde- $\mathrm{SO}_{2}$ adducts causes a clear depreciation of the orthonasal aroma quality in wines. Furthermore, this depreciation is more evident 
when the total aldehyde levels are high. From a descriptive point of view, the fruity character of young wines is masked by showing attributes that define oxidation. Quality detriment begins at a tested level 4 , which contains the following aldehyde concentrations: $13 \mu \mathrm{g} / \mathrm{L}$ of methional, $49 \mu \mathrm{g} / \mathrm{L}$ of phenylacetaldehyde, $17 \mu \mathrm{g} / \mathrm{L}$ of isobutyraldehyde, $12 \mu \mathrm{g} / \mathrm{L}$ of 2-methylbutanal and $24 \mu \mathrm{g} / \mathrm{L}$ of 3-methylbutanal. More than $75 \%$ of recently opened commercial wines contain concentrations of total aldehydes higher than these, therefore, it seems reasonable to look for tools that reduce the presence of aldehydes responsible for oxidation aromas in wines.

Working with white wine, mixed ion exchange resins have offered the best aldehyde removal results, maintaining, predominantly, the $\mathrm{pH}$ and total acidity, although reducing the colour by at least $20 \%$. On the other hand, the addition of sulphur dioxide only significantly improves the removal of acetaldehyde and phenylacetaldehyde using pure ion exchange resins.

Finally, the resin that has offered the best results has been the Strata X-A resin, which provides around $11-17 \%$ removal for isobutyraldehyde, $31-47 \%$ for 2 -methylbutanal, $29-31 \%$ for 3-methylbutanal, 33-37\% for methional, $78-86 \%$ for phenylacetaldehyde and $3-10 \%$ for acetaldehyde. However, due to the dose of resin used in the experiment $(10 \mathrm{~g} / \mathrm{L})$, further investigation of this issue on an industrial scale would be necessary in order to reach applicability conclusions.

Author Contributions: Conceptualization, V.F. and A.E.; experimental design, A.M.-C., M.B. and M.-P.S.-N.; methodology, A.M.-C., M.B. and A.d.-1.-F.-B.; investigation, A.M.-C., M.B., A.d.-1.-F.-B. and M.-P.S.-N.; writing-original draft preparation, A.M.-C. and A.E.; writing-review and editing, M.B., A.d.-1.-F.-B., M.-P.S.-N., A.E. and V.F.; supervision and funding acquisition, V.F. and A.E. All authors have read and agreed to the published version of the manuscript.

Funding: This work has been funded by the Spanish MINECO (Project AGL2014-59840 and AGL201787373-C3-1-R) and partly cofounded by the European Union (FEDER). Founding from Diputación General de Aragón (T53) and Fondo Social Europeo is acknowledged.

Acknowledgments: A.M.-C. has received a grant from the Spanish FPI program. M.-P.S.-N. acknowledges the Spanish National Research Agency (AEI), the Ministry of Science, Innovation, and Universities (MICIU) and the European Social Fund for her postdoctoral fellowship: Ramón y Cajal Program (RYC2019-027995-I/AEI/10.13039/501100011033). M.B. would like to acknowledge AEI and MICIU for her "Juan de la Cierva-Incorporación" postdoctoral grant IJC2018-037830-I.

Conflicts of Interest: The authors declare no conflict of interest.

\section{References}

1. Singleton, V.L.; Kramling, T.E. Browning of white wines and an accelerated test for browning capacity. Am. J. Enol. Viticult. 1976, 27, 157-160.

2. Escudero, A.; Cacho, J.; Ferreira, V. Isolation and identification of odorants generated in wine during its oxidation: A gas chromatography-olfactometric study. Eur. Food Res. Technol. 2000, 211, 105-110. [CrossRef]

3. Escudero, A.; Asensio, E.; Cacho, J.; Ferreira, V. Sensory and chemical changes of young white wines stored under oxygen. An assessment of the role played by aldehydes and some other important odorants. Food Chem. 2002, 77, 325-331. [CrossRef]

4. Ferreira, A.C.S.; Oliveira, C.; Hogg, T.; de Pinho, P.G. Relationship between potentiometric measurements, sensorial analysis, and some substances responsible for aroma degradation of white wines. J. Agric. Food Chem. 2003, 51, 4668-4672. [CrossRef] [PubMed]

5. Ugliano, M.; Kwiatkowski, M.J.; Travis, B.; Francis, I.L.; Waters, E.J.; Herderich, M.J.; Pretorius, I.S. Post-bottling management of oxygen to reduce off-flavour formation and optimise wine style. Aust. N. Z. Wine Ind. J. 2009, 24, $24-28$.

6. Cullere, L.; Cacho, J.; Ferreira, V. An assessment of the role played by some oxidation-related aldehydes in wine aroma. J. Agric. Food Chem. 2007, 55, 876-881. [CrossRef] [PubMed]

7. Escudero, A.; Hernandez-Orte, P.; Cacho, J.; Ferreira, V. Clues about the role of methional as character impact odorant of some oxidized wines. J. Agric. Food Chem. 2000, 48, 4268-4272. [CrossRef]

8. Bueno, M.; Carrascón, V.; Ferreira, V. Release and Formation of Oxidation-Related Aldehydes during Wine Oxidation. J. Agric. Food Chem. 2016, 64, 608-617. [CrossRef]

9. de Azevedo, L.C.; Reis, M.M.; Motta, L.F.; da Rocha, G.O.; Silva, L.A.; de Andrade, J.B. Evaluation of the formation and stability of hydroxyalkylsulfonic acids in wines. J. Agric. Food Chem. 2007, 55, 8670-8680. [CrossRef] 
10. Bueno, M.; Zapata, J.; Ferreira, V. Simultaneous determination of free and bonded forms of odor-active carbonyls in wine using a headspace solid phase microextraction strategy. J. Chromatogr. A 2014, 1369, 33-42. [CrossRef]

11. Ferreira, V.; Bueno, M.; Franco-Luesma, E.; Cullere, L.; Fernandez-Zurbano, P. Key Changes in Wine Aroma Active Compounds during Bottle Storage of Spanish Red Wines under Different Oxygen Levels. J. Agric. Food Chem. 2014, 62, 10015-10027. [CrossRef]

12. Kecili, R.; Nivhede, D.; Billing, J.; Leeman, M.; Sellergren, B.; Yilmaz, E. Removal of Acrolein from Active Pharmaceutical Ingredients Using Aldehyde Scavengers. Org. Process Res. Dev. 2012, 16, 1225-1229. [CrossRef]

13. Branton, P.J.; McAdam, K.G.; Winter, D.B.; Liu, C.; Duke, M.G.; Proctor, C.J. Reduction of aldehydes and hydrogen cyanide yields in mainstream cigarette smoke using an amine functionalised ion exchange resin. Chem. Cent. J. 2011, 5. [CrossRef]

14. Sun, W.J.; Zhang, M.; Chen, H.Z.; Zheng, D.D.; Fang, Z.X. Effects of deodorization on the physicochemical index and volatile compounds of purple sweet potato anthocyanins (PSPAs). LWT Food Sci. Technol. 2016, 68, 265-272. [CrossRef]

15. Rütti, D.P.; Lacroix, C.; Jeremic, T.; Mathis, M.; Die, A.; Vollenweider, S. Development of a reversible binding process for in situ removal of 3-hydroxypropionaldehyde during biotechnological conversion of glycerol. Biochem. Eng. J. 2011, 55, 176-184. [CrossRef]

16. Mendonca, A.D.M.; de Oliveira, A.V.B.; Cajaiba, J. A Comparison between Continuous and Batch Processes to Capture Aldehydes and Ketones by Using a Scavenger Resin. Org. Process Res. Dev. 2017, 21, 1794-1800. [CrossRef]

17. Parliament, T.H. Applications of a Microextraction Class Separation Technique to the Analysis of Complex Flavor Mixtures. In Flavor Analysis; American Chemical Society: Washington, DC, USA, 1998; pp. 8-21.

18. Kontogiannopoulos, K.N.; Patsios, S.I.; Mitrouli, S.T.; Karabelas, A.J. Tartaric acid and polyphenols recovery from winery waste lees using membrane separation processes. J. Chem. Technol. Biotechnol. 2017, 92, 2934-2943. [CrossRef]

19. Walker, T.; Morris, J.; Threlfall, R.; Main, G. Quality, sensory and cost comparison for pH reduction of Syrah wine using ion exchange or tartaric acid. J. Food Qual. 2004, 27, 483-496. [CrossRef]

20. Ibeas, V.; Correia, A.C.; Jordao, A.M. Wine tartrate stabilization by different levels of cation exchange resin treatments: Impact on chemical composition, phenolic profile and organoleptic properties of red wines. Food Res. Int. 2015, 69, 364-372. [CrossRef]

21. Lasanta, C.; Caro, I.; Perez, L. The influence of cation exchange treatment on the final characteristics of red wines. Food Chem. 2013, 138, 1072-1078. [CrossRef]

22. de-la-Fuente-Blanco, A.; Saenz-Navajas, M.P.; Ferreira, V. On the effects of higher alcohols on red wine aroma. Food Chem. 2016, 210, 107-114. [CrossRef] [PubMed]

23. Jacukowicz-Sobala, I.; Kociolek-Balawejder, E. The use of reactive polymers for removing residual aldehydes from aqueous and organic solutions. Przem. Chem. 2006, 85, 915-919.

24. Bueno, M.; Marrufo-Curtido, A.; Carrascon, V.; Fernandez-Zurbano, P.; Escudero, A.; Ferreira, V. Formation and Accumulation of Acetaldehyde and Strecker Aldehydes during Red Wine Oxidation. Front. Chem. 2018, 6. [CrossRef]

25. Parr, W.V.; Heatherbell, D.; White, K.G. Demystifying wine expertise: Olfactory threshold, perceptual skill and semantic memory in expert and novice wine judges. Chem. Senses 2002, 27, 747-755. [CrossRef] [PubMed]

26. AENOR. Sensory Analysis-Apparatus -Wine-Tasting Glass (ISO 3591:1977); UNE 87022:1992; AENOR: Madrid, Spain, 1992.

27. Abric, J.-C. La recherche du noyau central et de la zone muette des représentations sociales. In Méthodes D'étude des Représentations Sociales; Érès: Toulouse, France, 2005; pp. 59-80.

28. Ferrero-del-Teso, S.; Arias, I.; Escudero, A.; Ferreira, V.; Fernandez-Zurbano, P.; Saenz-Navajas, M.P. Effect of grape maturity on wine sensory and chemical features: The case of Moristel wines. LWT Food Sci. Technol. 2020, 118. [CrossRef]

29. OIV. Determination of total acidity. In Compendium of International Methods of Analysis; OIV-MA-AS313-01:R2015; OIV: Paris, France, 2019.

30. OIV. Determination of pH. In Compendium of International Methods of Analysis of Wines and Musts; OIV-MA-AS313-15:R2011; OIV: Paris, France, 2019.

31. OIV. OIV-MA-AS323-04A Sulphur dioxide. In Compendium of International Methods of Analysis; OIV: Paris, France, 2009.

32. OIV. Chromatic Characteristics. In Compendium of International Methods of Analysis; OIV: Paris, France, 2009.

33. Ribéreau-Gayon, P.; Glories, Y.; Maujean, A.; Dubourdieu, D. Handbook of Enology. Volume 2. The Chemistry of Wine Stabilization and Treatments, 2nd ed.; John Wiley \& Sons: Chichester, UK, 2006.

34. Saenz-Navajas, M.P.; Gonzalez-Hernandez, M.; Campo, E.; Fernandez-Zurbano, P.; Ferreira, V. Orthonasal aroma characteristics of Spanish red wines from different price categories and their relationship to expert quality judgements. Aust. J. Grape Wine R. 2012, 18, 268-279. [CrossRef]

35. Coetzee, C.; Buica, A.; du Toit, W.J. The Use of $\mathrm{SO} 2$ to Bind Acetaldehyde in Wine: Sensory Implications. S. Afr. J. Enol. Vitic. 2018, 39, 157-162. [CrossRef]

36. Hermosín, I. Resinas de intercambio iónico: Estado del arte y proyecciones futuras. In Proceedings of the Enoforum, Vincenza, Italy, 16-18 May 2017. 